\title{
REGIONAL SIMULATION WITH THE PRECIS MODEL
}

\author{
SIMULACIÓN REGIONAL CON EL MODELO PRECIS
}

Mark Falvey ${ }^{1}$

During 2006 the Geophysics Department of the University of Chile conducted a series of high resolution regional climate model (RCM) simulations for Chile's National Environmental Commission (CONAMA). The study employed a dynamical model (PRECIS) to produce spatially detailed climate projections for Chile under two different emissions scenarios. The results of the simulations were made freely available for use by the scientific community, industry and policy makers.

Today the PRECIS database remains an important resource for the analysis of climate change in Chile, especially in areas such as Patagonia where observations are sparse and climate variables such as temperature and precipitation exhibit extremely sharp spatial gradients that are not resolved by global models. In this presentation we provide an overview of the PRECIS project. We begin with a brief discussion of the motivation (section 2) and configuration (section 3) for the regional simulations. In section 4 selected PRECIS results are shown focusing on temperature and precipitation predictions in the Magellan region.

\section{MOTIVATION}

Most current knowledge about how the world's climate is likely to change as a result of increasing greenhouse gas emissions is based on numerical simulations using global climate models (GCMs). GCMs describe important physical elements and processes in the atmosphere, oceans and land surface that make up the climate system. The conclusions of the latest IPCC Assessment report were based on simulations from over 20 different global models operated by a similar number of scientific agencies worldwide. A major disadvantage of GCMs is their spatial scale, which is typically a few hundred kilometers in resolution. In order to study the impacts of climate change, it is necessary to predict changes on much finer scales. One of the techniques for doing so is through the use of Regional Climate Models (RCMs), which have the potential to improve the representation of the climate information used to assess vulnerability to climate change.

The need for RCM's is especially evident in Chile where, due to the sharp differences in eleva-

1 Profesor Experto, Departamento de Geofísica, Universidad de Chile. falvey@dgf.uchile.cl. 
tion from the coast to Cordillera, local climate can vary enormously over spatial scales of just several kilometers. From Figure 1 we see the GCM representation of Chile's topography is both considerably wider and lower than reality. In the Magellan's the topography of the GCMs doesn't exceed $1000 \mathrm{~m}$ (on average it is $\sim 500$ ) in any of the models. The reduced effective barrier height of the Andes in the GCMs leads to a significant under prediction of orographic precipitation enhancement on the upwind (westward) slopes of the mountains. For example, west of the Patagonian icefields annual rainfall is known to be very high - anywhere between $3 \mathrm{~m}$ and $6 \mathrm{~m}$ annually (e.g., DGA 2007). In contrast, most GCMs predict annual rainfall of less than half this amount. Furthermore, the sharp transition from a wet to arid climate that occurs across the main divide is poorly captured by the global models. The GCMs are also unable to produce significant amounts of snowfall during precipitation events in the mountains because the model surface is almost always below the height of the freezing level. As such, important cryological features including the Patagonian icefields are absent in the global simulations.

\section{The PRECIS Regional Climate Simulations}

\section{The PRECIS model}

PRECIS stands for "Providing Regional Climates for Impacts Studies". It is a regional modeling system developed at the Hadley Center at the UK Met Office. PRECIS is based on an improved version of the atmospheric component of the Hadley Centre coupled global model, HadCM3. PRECIS is a limited area model and may be used with horizontal

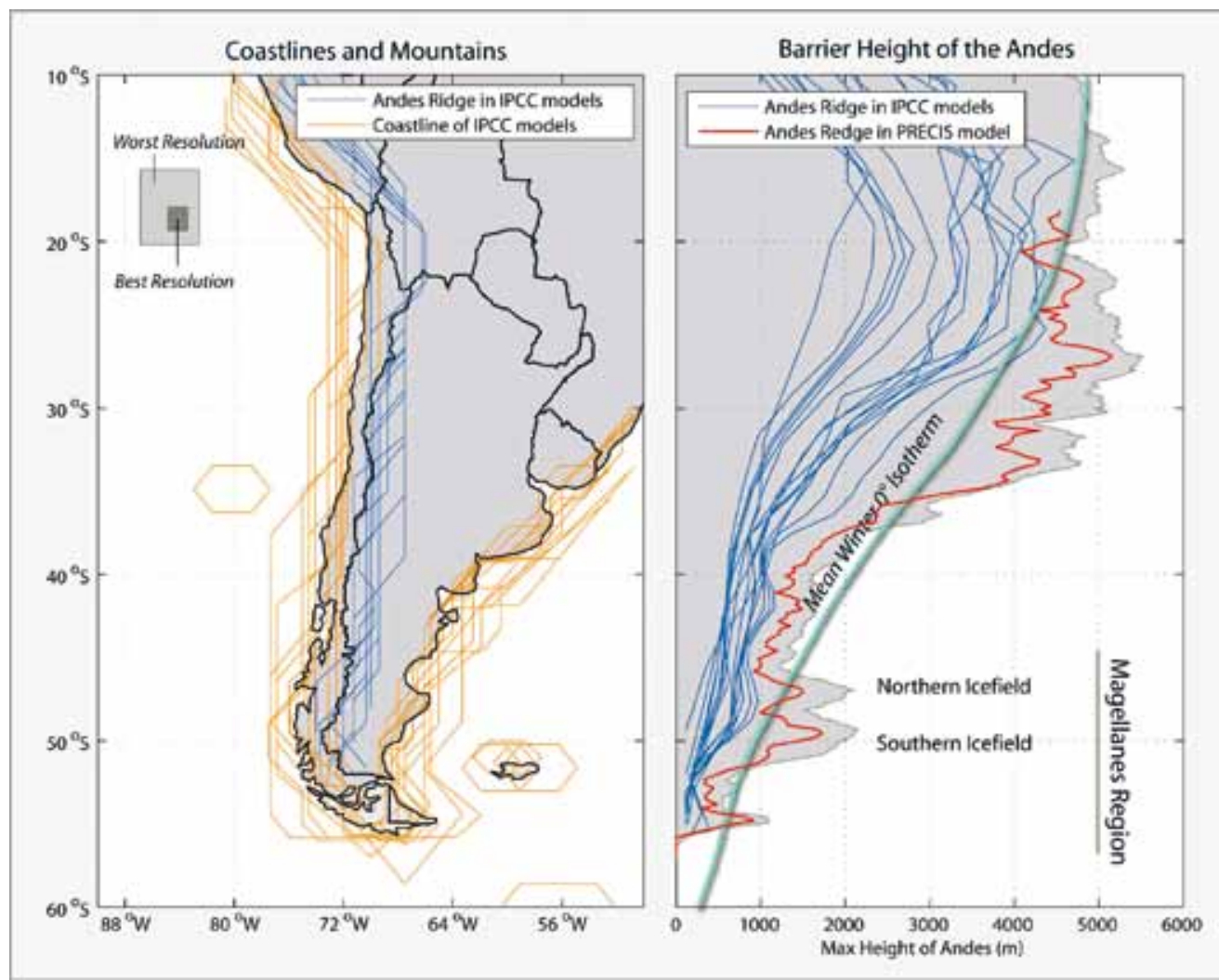

Fig. 1. Representation of the topography of Southern South America in the AR4 series of global climate models. The left panel shows the location of the peak of the Andes cordillera (blue lines) and the location of the coastline (orange lines) for about 20 of the available GCM. The right panel compares the effective barrier height of the Andes with the AR4 models (blue lines). In all cases the model barrier height is well below the observed value (grey filled region) and also well below the mean winter $0^{\circ}$ isotherm (light blue line) derived from NCEP-NCAR reanalysis. The topography of the high resolution (25 km) PRECIS regional model (red line) has a barrier height much closer to that of the real topography. 
resolutions of 50 and $25 \mathrm{~km}$ with 19 levels in the atmosphere (from the surface to $30 \mathrm{~km}$ in the stratosphere) and four levels in the soil. Further information on PRECIS, including detailed documentation, may be obtained at the Hadley center website ${ }^{1}$.

The initial and boundary conditions for PRECIS are provided by HadAM3P - a global atmosphere-only model with a resolution of order $150 \mathrm{~km}$, forced by surface boundary conditions (sea-surface temperature and sea-ice fraction) from HadCM3 and observations. PRECIS uses the same formulation of the climate system as its parent GCM which helps to ensure that the regional model provides high-resolution regional climate change projections consistent with the continental scale climate change from the GCM.

\section{Model Configuration for Chile}

PRECIS was configured with a model domain spanning all of continental Chile (Fig. 2). A grid spacing of $25 \mathrm{~km}$ was employed - at this resolution the major topographic features within the model domain (e.g., the height of the Andes cordillera) are well resolved (Fig.1).

Simulations of 30 year periods were made for three climate scenarios. In the simulation labeled BASELINE the model was integrated for the period 1961 - 1990 using boundary conditions and greenhouse gas concentrations representative of those observed during this period. The BASELINE simulation was compared with observations and found to have a good performance in reproducing spatial and seasonal patterns of key climate variables such as temperature, precipitation and winds (e.g., Garreaud \& Falvey, 2008). This simulation serves a reference for the calculation of projected climate change under future climate scenarios.

Future climate simulations were made for the period 2070-2100 employing boundary conditions and greenhouse gas concentrations based on moderate (B2) and severe (A2) SRES emissions scenarios (e.g., Nakicenovic et al., 2000). The emissions scenarios and time period were chosen in order to best detect the regional climate change signal. However, it must be stressed that there is a large uncertainty in the PRECIS projections

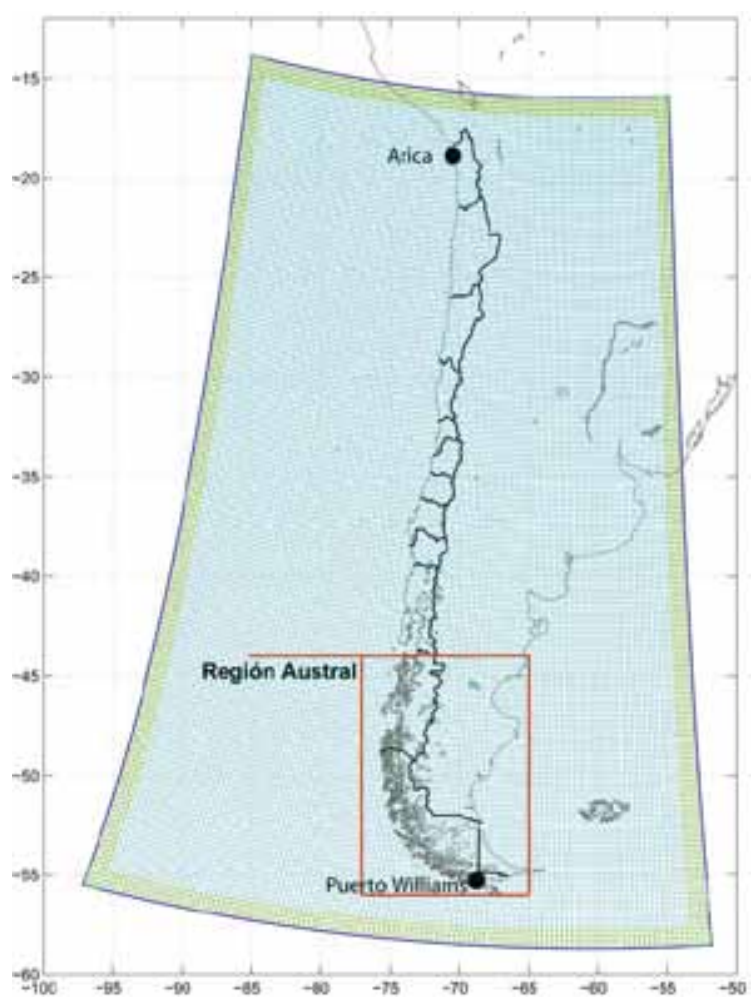

Fig. 2. Computational domain of the PRECIS model. The blue dots show the location of individual grid points. The grid appears distorted because the model is formulated on a rotated pole coordinate system. The red rectangle indicates the area presented in figure 3 .

simply because they are based on boundary data from just a single GCM. Ideally, several regional simulations based on multiple global models should be performed. However, computational limitations and a lack of alternative boundary condition data prevented running more simulations. PRECIS users are recommended to place their results in context through careful inter-comparison with alternative climate change projections.

Further details of regarding the PRECIS simulations, including the model validation and discussion of the projected climate changes may be found in the project report (CONAMA 2006). The PRECIS database is freely and publicly available via Internet ${ }^{2}$ for use in impact studies. On this site on-line tools are provided allowing access to spatial maps and time series data. 


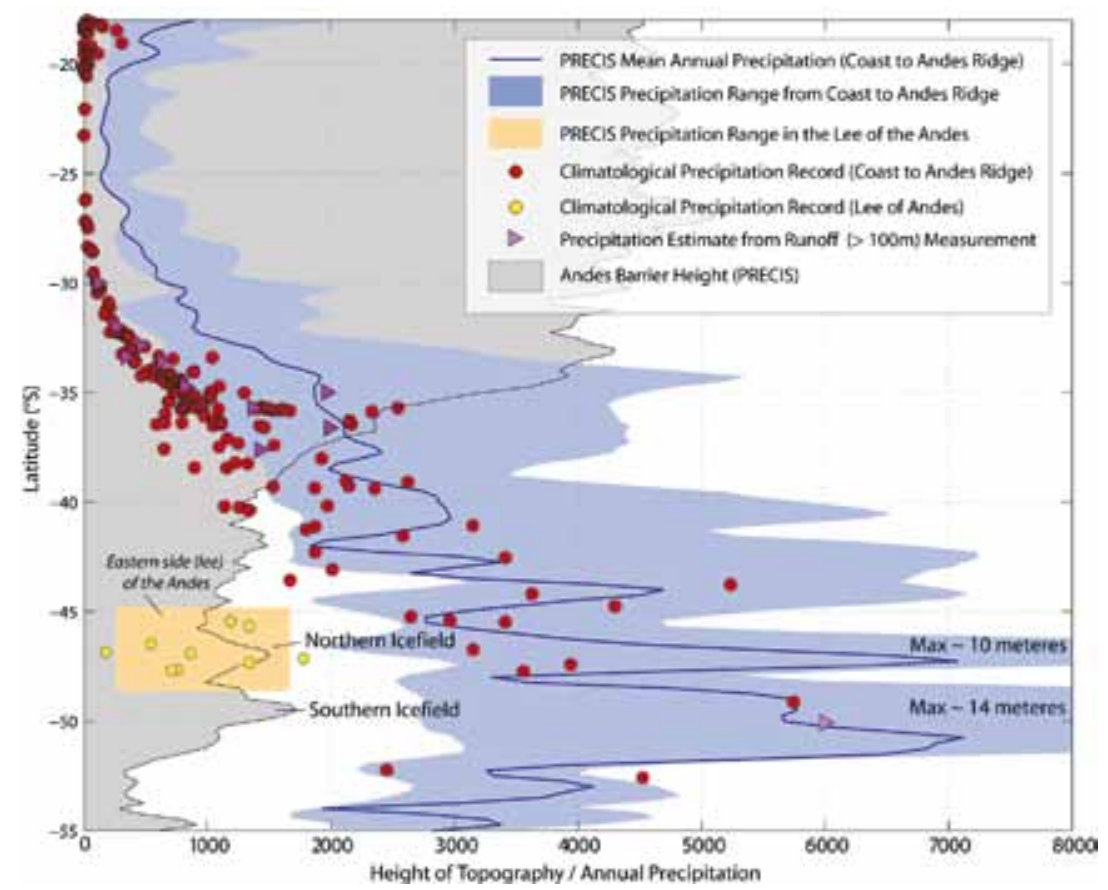

Fig. 3. Comparison of the annual mean PRECIS precipitation with observations along a meridional cross section following the western (Chilean) side of the Andes (vertical axis). The blue region shows the range of modeled annual precipitation (mm) between the Chilean coast and the peak of the Andes (data taken from the BASELINE simulation). The red dots show the observed annual precipitation $(\mathrm{mm})$ from a climatological dataset (Aceituno et al, 2008) of raingauge measurements. At the latitudes corresponding to the locations of the northern and southern Patagonian icefields, the maximum precipitation values exceed the axis limits and reach values of $10 \mathrm{~m}$ and $14 \mathrm{~m}$ respectively. Pink triangles are estimates of mean precipitation derived from annual runoff measurements in high altitude watersheds. The yellow dots show annual precipitation observations in a rain shadow region east of the northern icefield. The light orange rectangle indicates the precipitation predicted by PRECIS in the same area.

PRECIS Results in the Magellan Region

In the following we comment briefly on some results from the PRECIS model in the Magellan region. Fig. 4 shows the BASELINE simulation and projected (A2) changes in temperature and precipitation for the summer (DJF) and winter months (JJA).

PRECIS reproduces considerable detail in the mean (BASELINE) temperature field (top left), mainly because of the large surface height variability within the area presented. Despite the complexity of the topography, the projected rises in temperature are quite uniform, typically between 2 and 4 degrees, the highest increases occurring during summer and over land areas. These values are quite similar to the mean changes predicted by the ensemble mean of the GCM's (e.g., Falvey \& Garreaud 2008). Over the Patagonian icefields, predicted temperature changes are smaller than over the surrounding lowlands. This most likely occurs because the model develops a permanent snow layer in this region which acts to moderate the temperature changes associated with global warming.

The lower section of the Figure 3 shows the BASELINE precipitation and projected precipitation changes for the summer (DJF) and winter months (JJA). The BASELINE precipitation field is characterized by a sharp transition from wet to dry conditions on the western and eastern sides of the Andes, a climatological feature that agrees well with raingauge measurements (Figure 3). On the upwind slopes of the mountains very high seasonal precipitation totals are simulated (1-2 $\mathrm{m}$ ) with little seasonal variation. Annual precipitation totals to in this region compare well with available observations (Figure 3). Highest precipitation rates are predicted over the northern and southern Patagonian icefields, where annual totals exceed $10 \mathrm{~m}$. In this region almost all of the simulated precipitation is in the form of snow, and the PRECIS simulations (which include a basic sur- 

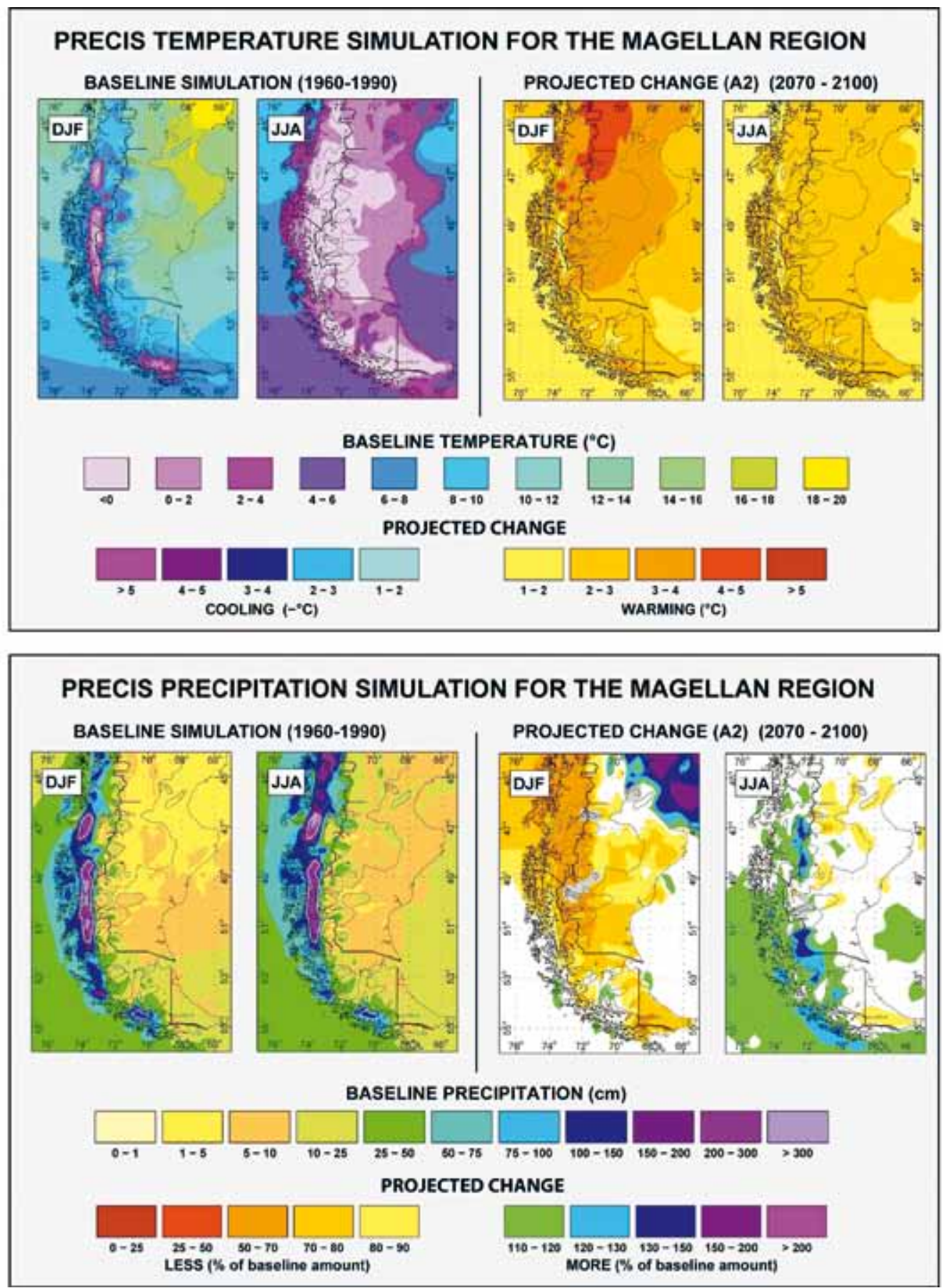

Fig. 4. PRECIS results in the Magellan region. The upper section of the graph shows the BASELINE simulation and projected changes in temperature for summer (December-January-February - DJF) and winter (June-July-August). The projected changes are shown only for the A2 (severe) emissions scenario. The lower section is similar, but shows the BASELINE values and projected changes for precipitation. Note the non-linear precipitation color scale. Projected precipitation changes are expressed as a percentage of the BASELINE value. The white contours on the BASELINE precipitation maps indicate areas where the model predicts a net snow accumulation that exceeds ablation, leading to a permanently growing snow pack. In such areas glaciers may be expected to form. 
face energy balance component) predict an annual snow accumulation that significantly exceeds annual water loss due to ablation processes (sublimation and melting). Such conditions are necessary for glaciers and icefields to form.

The projected precipitation changes under the A2 scenario demonstrate opposing spatial signals for the summer and winter months. During summer, substantial drying is predicted over the continental region east of the Andes at latitudes higher than about $48^{\circ} \mathrm{S}$. During winter, a significant intensification of precipitation is predicted over and to the west of the Andes at these latitudes. These contrasting seasonal patterns of precipitation trends appear to be related to large scale changes in the zonal circulation (not shown) which intensifies during winter and weakens during summer under the A2 scenario.

\section{ACKNOWLEDGEMENTS}

The PRECIS regional modeling project was sponsored by CONAMA with additional financial support from CONICYT project ACT-19. The author would like to thank all those involved in PRECIS climate simulation project, including Rodrigo Sanchez, Humberto Fuenzalida, Maisa Rojas, Rene Garreaud and Patricio Acietuno.

\section{LITERATURE CITED}

Aceituno, P, M. Prieto, M. Solari, A. Martínez, G. Poveda \& M. Falvey 2008. The 1877-1878 El Niño episode: associated impacts in South America, Climate Change, doi:10.1007/ s10584-008-9470-5

CONAMA 2006. Estudio de la Variabilidad Climática en Chile para el Siglo XXI, Informe Final DGA 1987, Balance Hídrico de Chile, Dirección General de Aguas, Santiago, Chile.

Falvey, M. \& R. Garreaud 2008. Regional Cooling in a Warming World: Recent Temperature Trends in the Southeast Pacific and along the West Coast of Subtropical South America (19792006), Journal of Geophysical Research, 114: D04102,

Garreaud, R. \& M. Falvey 2008. The coastal winds off western subtropical South America in future climate scenarios. International Journal of Climatology, doi: 10.1002/joc.1716

Nakicenovic N. \& Coauthors 2000. IPCC Special Report on Emissions Scenarios, 734599 pp., Cambridge University Press, New York. 